\title{
Psychometric properties of instruments to measure parenting practices and children's movement behaviors in low-income families from Brazil
}

Widjane Sheila Ferreira Goncalves ${ }^{1}$, Rebecca Byrne ${ }^{1}$, Pedro Israel Cabral de Lira², Marcelo Tavares Viana ${ }^{2}$ and Stewart G. Trost ${ }^{1,3^{*}}$

\begin{abstract}
Background: Childhood obesity has increased remarkably in low and middle-income (LMIC) countries. Movement behaviors (physical activity, screen time, and sleep) are crucial in the development of overweight and obesity in young children. Yet, few studies have investigated the relationship between children's movement behaviors and parenting practices because validated measures for use among families from LMIC are lacking. This study evaluated the psychometric properties of previously validated measures of young children's physical activity, screen time, and sleep and parenting practices, translated and culturally adapted to Brazilian families.

Methods: A total of 78 parent-child dyads completed an interviewer-administered survey twice within 7 days. Child physical activity, sedentary time and sleep were concurrently measured using a wrist-worn accelerometer. Internal consistency and test-retest reliability was assessed using McDonald's Omega and Intraclass Correlation Coefficients (ICC's). Concurrent validity was evaluated by calculating Spearman correlations between parent reported child behaviors and accelerometer measured behaviors.

Results: Seventeen of the 19 parenting practices scales exhibited acceptable internal consistency reliability $(\Omega \geq$ 0.70). Test-retest reliability ICC's were acceptable and ranged from $0.82-0.99$. Parent reported child physical activity was positively correlated with objectively measured total movement (rho $=0.29-0.46, p<.05)$ and energetic play (rho $=0.29-0.40, p<.05)$. Parent reported child screen time was positively correlated with objectively measured sedentary time; (rho $=0.26, p<.05)$, and inversely correlated with total movement (rho $=-0.39--0.41, p<.05$ ) and energetic play (rho $=-0.37--0.41, p<.05$ ). Parent reported night-time sleep duration was significantly correlated with accelerometer measured sleep duration on weekdays (rho $=0.29, p<.05$ ), but not weekends.

Conclusions: Measurement tools to assess children's movement behaviors and parenting practices, translated and culturally adapted for use in Brazilian families, exhibited acceptable evidence of concurrent validity, internal consistency, and test-retest reliability.
\end{abstract}

Keywords: Psychometric properties, Parenting, Physical activity, Screen time, Sleep

\footnotetext{
* Correspondence: s.trost@qut.edu.au

${ }^{1}$ Centre for Children's Health Research, School of Exercise and Nutrition

Sciences, Queensland University of Technology, Brisbane, Australia

${ }^{3}$ Centre for Children's Health Research (CCHR), Level 6, 62 Graham St, South

Brisbane, QLD 4101, Australia

Full list of author information is available at the end of the article
}

(c) The Author(s). 2021 Open Access This article is licensed under a Creative Commons Attribution 4.0 International License, which permits use, sharing, adaptation, distribution and reproduction in any medium or format, as long as you give appropriate credit to the original author(s) and the source, provide a link to the Creative Commons licence, and indicate if changes were made. The images or other third party material in this article are included in the article's Creative Commons licence, unless indicated otherwise in a credit line to the material. If material is not included in the article's Creative Commons licence and your intended use is not permitted by statutory regulation or exceeds the permitted use, you will need to obtain permission directly from the copyright holder. To view a copy of this licence, visit http://creativecommons.org/licenses/by/4.0/. The Creative Commons Public Domain Dedication waiver (http://creativecommons.org/publicdomain/zero/1.0/) applies to the data made available in this article, unless otherwise stated in a credit line to the data. 


\section{Background}

Childhood obesity in children under five is a global public health problem [1], and particularly problematic for children residing in low- and middle-income countries (LMIC) [2]. Worldwide, approximately three quarters of all overweight and obese children live in LMIC's - with the highest prevalence in South America [2]. In Northeast Brazil, it is estimated that 1 in 3 children are either overweight or obese [3]. Of concern, childhood obesity is associated with immediate and long-term health problems. The immediate problems of obesity in childhood include, elevated blood pressure, insulin resistance, and psychosocial health outcomes, such as lower self-esteem and higher prevalence of bullying [4-6]. The long-term health problems include increased risk of cardiovascular disease and type 2 diabetes [7]. Overweight and obesity during early childhood also increases the risk of obesity in adolescence and adulthood [8]. Children who are overweight in the first 5 years of life are five times more likely to be overweight at age 12 compared to children in the healthy weight range [9].

Movement behaviors are crucial in the prevention of overweight and obesity [10], with regular physical activity, limited sedentary screen time, and adequate sleep duration as the ideal combination [11]. The World Health Organization recommends that preschool-aged children spend a minimum of 3 hours a day in a variety of physical activities, with 60 minutes of moderate to vigorous physical activity (MVPA); accumulate less than 60 minutes of sedentary screen time; and sleep between 10 to 13 hours every day [12]. However, little is known about the proportion of South American children meeting these recommendations, including children from Brazil [13]. Currently there is substantial inconsistency in how obesity-related movement behaviors are measured, and validated assessment tools culturally adapted to LMIC families are lacking.

Parents plays a significant role in the development of children's physical activity, screen time and sleep behaviors [14-17]. Parenting practices are the strategies parents use to assist or support children in their socialization goals, including the establishment of healthy lifestyle behaviors [18]. Logistic support, modeling, co-participation, and setting rules and limits are key parenting practices associated with healthful movement behaviors in young children [19-21]. The vast majority of studies examining parenting practices and child health behaviors, however, have been conducted in families from high-income countries [22, 23]. No studies have investigated parenting practices related to young children's movement behaviours in families residing in LMIC countries. Accordingly, there is an urgent need for valid and reliable measures of parenting practices related to children's movement behaviors for use in LMIC families, as currently no such measures exist.
Knowing the parenting practices that support healthful movement behaviors in young children is a necessary prerequisite for the development of effective family-based interventions to prevent childhood obesity. To address these gaps in knowledge, the current study evaluated the internal consistency reliability, test-retest reliability and concurrent validity of previously validated measures of preschool-aged children's physical activity, screen time, and sleep and parenting practices, translated and culturally adapted to Brazilian families.

\section{Methods}

\section{Sample and recruitment}

Parent-child dyads attending two Early Childhood Education and Care Centers (ECEC) from Caruaru, Brazil (1 rural; 1 urban) were invited to participate in the study. Prior to conducting the study, the Director from each Centre was contacted by the principal investigator to explain the research and obtain permission for the Centre to participate. Subsequently, a flyer was distributed to all parents of children between the ages three and six, inviting them to attend a meeting to explain the research project in detail. During this meeting, participant information sheets and consent forms were distributed. Parents who agreed to participate returned a signed informed consent form to the principal investigator. For parents with low literacy level and their children informed consent was obtained from a legally authorized representative. Participating parents were asked to nominate a day and time during the following week they could attend the center for data collection. All recruitment and data collection activities were completed between May and June 2019. The research was approved by the Human Research Ethics Committee of the Queensland University of Technology, Brisbane/Australia (Approval No. 1800001141), and the Department of Education of Caruaru, Brazil (Approval Letter March 1, 2019). All methods were carried out in accordance with relevant guidelines and regulations of the Human Research Ethics Committee at Queensland University of Technology.

\section{Protocol}

Parents completed a survey measuring parenting practices and children's movement behaviors translated into Portuguese and adapted for use in Brazilian families [24]. The Portuguese and English versions of the survey are included as Supplementary material. Depending on literacy level, parents could complete the survey themselves, or have it administered to them as an interview. Each interview took approximately 45 minutes to complete. Parents with multiple children enrolled in the ECEC were instructed to complete the survey in relation to their first-born.

After completing the survey, participating children were outfitted with an accelerometer-based motion 
sensor on the non-dominant wrist to be worn 24 hours/ day (with the exception of bathing or swimming) for seven consecutive days. On completion of the 7-day monitoring period, parents returned the accelerometer to a member of the research team at the ECEC and completed the parent survey a second time. Participating parent-child dyads received an USD \$3.65 gift (soccer ball, skipping rope or peteca) in return for their time and effort.

\section{Measures}

The following socio-demographic information were collected: child's sex, date of birth, ethnicity, attendance at ECEC (part-time vs full-time), caregivers' age and gender, level of education, marital status, current employment status, household income, financial support from government 'Bolsa Família Programme' and number of residents at home.

\section{Parenting practices}

Parenting practices related to physical activity and screen time were measured using translated and culturally adapted versions of the measurement scales developed by Vaughn $[24,25]$. These scales measure parenting practices used to control or support children's physical activity and screen time. Controlling parenting practices included rules around active play indoors (12 items), rules around active play outdoors (4 items), use of physical activity to reward/control behaviour (5 items), limiting outdoor play due to weather ( 2 items), limiting, or monitoring of screen time (8 items), and use of screen time to reward/control child behaviour (4 items). Supportive parenting practices included explicit modelling and enjoyment of physical activity (10 items), verbal encouragement for physical activity (6 items), logistic support for sports (3 items), logistic support for active play (3 items), importance and value of physical activity (3 items), support/reinforcement from other adults (3 items), exposure to TV (3 items), and explicit modelling and enjoyment of screen time (6 items) [25]. Parenting practices related to sleep were measured using items adapted from the Bedtime Routines Questionnaire [26]. This questionnaire consists of 5 scales measuring routine behavior (4 items), routine environment (4 items), reactivity ( 4 items), adaptive activities (7 items), and maladaptive activities (6 items).

\section{Parent reported child health behaviours}

Children's physical activity was measured using a translated version of the Burdette outdoor playtime recall [27]. Parents reported the amount of time their child spent playing outdoor considering a typical weekday and a typical weekend day in the last month.
Child screen time was assessed using an adaptation of an instrument used in the Australian InFANT study [28]. Parents reported their child's screen time on a normal weekday and a normal weekend day based on a number of electronic devices. This included watching television programs and DVDs and videos viewing, using a computer, playing with an electronic game system (e.g. Nintendo DS, Playstation, Xbox), and using smartphones, iPads or Tablets. Night-time sleep duration was measured using items adapted from the Prevention of Overweight in Infancy randomized control trial [29]. Parents reported the time their child usually went to bed at night and the time the child woke up in the morning to start the day. These items assessed sleep on weekdays and weekend days separately.

\section{Accelerometer-measured movement behaviors}

Daily time spent in physically active movement behaviors was measured using the ActiGraph GT3X+ accelerometer (ActiGraph Corporation, Pensacola FL, USA). Raw accelerometer data $(30 \mathrm{~Hz})$ was downloaded and processed into physical activity metrics using a random forest physical activity classification algorithm specifically developed for children under five [30]. This validated machine learning algorithm uses 20 features extracted from the raw tri-axial acceleration signal to classify activity type and quantify daily time spent in sedentary activities (sitting or lying down), light-intensity activities and games (slow walking, standing, standing arts and crafts), walking, running, and moderate-tovigorous intensity activities and games (active games with balls, riding bikes/scooters). In a free-living evaluation, the random forest algorithm exhibited an overall classification accuracy of greater than $80 \%$. Total moment was calculated by summing daily time spent in light-intensity activities and games, walking, running, and moderate-to-vigorous activities and games; while energetic play was calculated by summing daily time spent in walking, running, and moderate-to-vigorous activities and games. Nighttime sleep duration was measured using the sleep/wake detection algorithm developed by Van Hees et al. [31]. Non-wear periods were identified by summing the 15 second windows in which the standard deviation of the vector magnitude was $<13$ $\mathrm{mg}$ for $>=30$ consecutive minutes [32]. The child's accelerometer data was included in the analyses if they had $\geq 5$ days in which wear time was 10 hours (600 minutes) or longer.

\section{Statistical analysis}

Means and standard deviations were calculated for the parenting practices scales and parent reported movement behaviors. The internal consistency of scales was evaluated using McDonald's Omega. Omega is a preferable indicator 
of internal consistency reliability because the measurement model assumed by Cronbach's alpha (equal factor loadings or essential tau equivalency) is typically not tenable in applied research [33]. One-week test-retest reliability was assessed by calculating Intraclass Correlation Coefficients (ICC); mode: two-way mixed; type: agreement). Omega was considered acceptable at $\geq 0.70$, while ICC's were considered acceptable at $\geq 0.75$ [34]. Evidence of concurrent validity for parent reported child physical activity, screen time, and sleep were evaluated by calculating Spearman correlations with accelerometer measured activity metrics, including sedentary time, total movement, energetic play, and sleep duration. Omega statistics were calculated using the MBESS package in R [35]. All other statistical procedures were performed using SPSS statistical software version 25 . Significance was set at an alpha level of 0.05 .

\section{Results}

Of the 132 families attending the two childcare services, 78 parent child-dyads (38 from an urban ECEC service and 40 from a rural ECEC service) consented to participate. Children were a mean age of $4.6 \pm 0.8$ years, $53 \%$ male, $42 \%$ mixed race, $52 \%$ attended the rural ECEC service, and $71 \%$ attended childcare half-time. Descriptive data regarding the parents is presented in Table 1. Due to low literacy, most parents $(N=70,90 \%)$ completed the survey as an interview-administered survey.

Internal consistencies (Omega), test-retest reliability coefficients (ICC) and means \pm SD for the parenting practices scales are reported in Table 2. McDonald's Omega for 17 of the 19 of the parenting practices scales were acceptable. Low internal consistencies were observed for the "support/reinforcement from other adults" $(\Omega=0.46-0.50)$ and "maladaptive activities on sleep" $(\Omega=35-0.38)$ scales. ICC's for the parenting practices scales were acceptable and ranged from ICC $=0.82$ 0.99 . However, the "logistic support for sports" scale exhibited low test-retest reliability $(\mathrm{ICC}=0.47)$. Means and SD's for parenting practice constructs measured at Time 1 and Time 2 were almost identical.

Means and standard deviations for the parent reported and accelerometer measured children's movement behaviors are reported in Table 3. Averaged over weekdays and weekend days, parent reported children's physical activity ranged from 192 to 195 minutes per day; screen time ranged from 197 to 199 minutes per day, while sleep duration ranged from 606 to 607 minutes per day. Based on the accelerometer data, children, on average, accumulated 437 minutes per day of sedentary time, 377 minutes per day of total movement, and 33 minutes per day of active play. Average night-time sleep duration was 505 minutes per day.
Table 1 Parent demographics and descriptive characteristics

\begin{tabular}{|c|c|}
\hline Variables & $\begin{array}{l}\text { Parents } \\
\mathrm{N}(\%) \\
\end{array}$ \\
\hline \multicolumn{2}{|l|}{ Sex } \\
\hline Female caregiver & $71(92)$ \\
\hline \multicolumn{2}{|l|}{ Age (years) } \\
\hline$\leq 24$ & $11(14)$ \\
\hline Between 25-35 & $43(56)$ \\
\hline$>36$ & $23(30)$ \\
\hline \multicolumn{2}{|l|}{ Marital status } \\
\hline Single & $17(22)$ \\
\hline Married & $19(25)$ \\
\hline Living with partner & $34(44)$ \\
\hline Separated/divorced & $6(8)$ \\
\hline Widowed & $1(1)$ \\
\hline \multicolumn{2}{|l|}{ Employment status } \\
\hline Employed full-time & $42(55)$ \\
\hline Employed part-time & $8(10)$ \\
\hline Casually employed & $13(17)$ \\
\hline Unemployed or retired & $14(18)$ \\
\hline \multicolumn{2}{|l|}{ Household income $^{a}$} \\
\hline$<=1$ wage & $53(69)$ \\
\hline Between 1 and 2 wage & $20(26)$ \\
\hline$>2$ wage & $4(5)$ \\
\hline \multicolumn{2}{|l|}{ Level of education } \\
\hline No study & $3(4)$ \\
\hline Elementary school & $42(54)$ \\
\hline High school & $19(25)$ \\
\hline Tertiary education & $10(13)$ \\
\hline Post-graduation & $3(4)$ \\
\hline \multicolumn{2}{|l|}{ Number of residents } \\
\hline$\leq 4$ & $51(66)$ \\
\hline$>4$ & $26(34)$ \\
\hline \multicolumn{2}{|l|}{ ‘Bolsa família’ programme ${ }^{b}$} \\
\hline Yes & $53(69)$ \\
\hline
\end{tabular}

Test-retest reliability coefficients and $95 \%$ confidence intervals for the parent reported children's movement behaviors are displayed in Table 4. ICC's for children's movement behaviors on weekdays, weekend days and the average of weekend and weekdays were excellent and ranged from 0.85 to 0.97 .

Spearman correlations between parent reported physical activity, screen time and sleep, and accelerometer measured physical activity, sedentary time and sleep are reported in Table 5. On weekdays, weekends, and the 
Table 2 Internal consistencies, test-retest reliability coefficients, and means ( \pm SD) for the parenting practices scales

\begin{tabular}{|c|c|c|c|c|c|}
\hline \multirow[t]{2}{*}{ Scale (\#items) } & \multicolumn{2}{|c|}{ Internal consistency $(\Omega)$} & \multirow{2}{*}{$\begin{array}{l}\text { Test- } \\
\text { retest } \\
\text { reliability } \\
\text { (ICC) }\end{array}$} & \multicolumn{2}{|c|}{ Mean \pm SD } \\
\hline & Time 1 & Time 2 & & Time 1 & Time 2 \\
\hline \multicolumn{6}{|l|}{ Controlling physical activity parenting practices } \\
\hline Rules around active play indoors & 0.85 & 0.81 & 0.90 & $2.3 \pm 0.5$ & $2.2 \pm 0.4$ \\
\hline Rules around active play outdoors & 0.71 & 0.79 & 0.96 & $3.2 \pm 1.4$ & $3.2 \pm 1.4$ \\
\hline Use of PA to reward/control child behavior & 0.88 & 0.88 & 0.92 & $2.9 \pm 1.4$ & $3.0 \pm 1.3$ \\
\hline Limiting outdoor play due to weather & 0.83 & 0.80 & 0.90 & $3.8 \pm 1.7$ & $3.7 \pm 1.5$ \\
\hline Limiting or monitoring of screen time & 0.85 & 0.89 & 0.97 & $1.8 \pm 0.9$ & $1.8 \pm 0.9$ \\
\hline Use of screen time to reward/control child behavior & 0.86 & 0.89 & 0.95 & $2.7 \pm 1.5$ & $2.8 \pm 1.5$ \\
\hline \multicolumn{6}{|l|}{ Supportive physical activity parenting practices } \\
\hline Explicit modeling and enjoyment of PA & 0.78 & 0.76 & 0.95 & $2.9 \pm 0.8$ & $2.9 \pm 0.7$ \\
\hline Verbal encouragement for PA & 0.71 & 0.71 & 0.84 & $3.1 \pm 1.0$ & $3.0 \pm 1.0$ \\
\hline Logistic support for sports & 0.70 & 0.63 & 0.47 & $0.8 \pm 0.4$ & $1.3 \pm 0.5$ \\
\hline Logistic support for active play & 0.80 & 0.71 & 0.91 & $2.6 \pm 1.5$ & $2.6 \pm 1.3$ \\
\hline Importance and value of PA & 0.83 & 0.78 & 0.82 & $4.2 \pm 0.7$ & $4.0 \pm 0.7$ \\
\hline Support/reinforcement from other adults & 0.50 & 0.46 & 0.75 & $3.8 \pm 0.7$ & $3.7 \pm 0.7$ \\
\hline \multicolumn{6}{|l|}{ Supportive screen parenting practices } \\
\hline Exposure to ST & 0.75 & 0.77 & 0.99 & $4.3 \pm 2.3$ & $4.3 \pm 2.3$ \\
\hline Explicit modeling and enjoyment of ST & 0.79 & 0.76 & 0.82 & $3.7 \pm 1.1$ & $3.7 \pm 0.9$ \\
\hline \multicolumn{6}{|l|}{ Sleep parenting practices } \\
\hline Consistency: routine behavior & 0.79 & 0.82 & 0.86 & $4.0 \pm 0.9$ & $4.1 \pm 0.9$ \\
\hline Consistency: routine environment & 0.78 & 0.75 & 0.88 & $4.3 \pm 0.8$ & $4.2 \pm 0.7$ \\
\hline Reactivity & 0.68 & 0.70 & 0.87 & $1.4 \pm 0.6$ & $1.5 \pm 0.6$ \\
\hline Adaptive activities & 0.73 & 0.77 & 0.91 & $3.7 \pm 0.8$ & $3.6 \pm 0.7$ \\
\hline Maladaptive activities & 0.35 & 0.38 & 0.76 & $2.5 \pm 0.6$ & $2.5 \pm 0.6$ \\
\hline
\end{tabular}

Legend: $\Omega$ McDonald's Omega, ICC Intraclass correlation coefficient, PA Physical activity, SD Standard deviation, ST Screen time

average of weekdays and weekends, parent reported physical activity was positively and significantly correlated with total movement $(\mathrm{rho}=0.29-0.46, p<.05)$ and active play (rho $=0.29-0.40, p<.05)$. Averaged over weekdays and weekend days, parent reported screen time was significantly and positively correlated with objectively measured sedentary time; (rho $=0.26, p<.05$ ), and significantly inversely correlated with total movement (rho $=-0.39--0.41, p<.05)$ and active play (rho $=-0.37--0.41, p<.05)$. Parent reported night-time sleep duration was significantly and positively correlated with accelerometer measured sleep duration on weekdays (rho $=0.29, p<.05$ ), but not weekends.

\section{Discussion}

This study evaluated the psychometric properties of instruments to measure children's movement behaviors and parenting practices in low-income families from Brazil. To our knowledge, it is the first study evaluating tools to measure these concepts in disadvantaged families from urban and rural Brazil and more broadly, families residing in LMIC. The internal consistency for 17 of the 19 parenting practices scales were acceptable, and with the exception of "logistic support for sports", test-retest reliability for the parenting practices scales and children's movement behaviors were high $(\geq 0.75)$. Correlations between parent report measures of child physical activity, screen time and sleep, and accelerometer measured children's movement behaviors were statistically significant and in expected direction. These findings indicate that the measures have evidence of concurrent validity, internal consistency, and test-retest reliability in Brazilian families.

The parenting practices scales exhibited satisfactory internal consistency reliability at both Time 1 and Time 2. However, there were some notable exceptions. The "support/reinforcement from other adults" and "maladaptive activities on sleep" scales exhibited low internal consistency. Comparing our results to those reported in the validation study involving families in the United States [25], it is interesting to note that a low alpha coefficient $(\alpha=0.54)$ was also reported for the "support/ 
Table 3 Descriptive data for the parent reported and accelerometer measured children's movement behaviors

\begin{tabular}{|c|c|c|c|c|}
\hline & & \multicolumn{3}{|l|}{ Mean \pm SD } \\
\hline & & Week days & Weekend days & Average of weekdays and weekend days \\
\hline \multicolumn{5}{|c|}{ Parent reported (minutes) } \\
\hline \multirow[t]{2}{*}{ Physical activity } & Time 1 & $153 \pm 71$ & $236 \pm 118$ & $195 \pm 88$ \\
\hline & Time 2 & $146 \pm 63$ & $236 \pm 112$ & $192 \pm 82$ \\
\hline \multirow[t]{2}{*}{ Screen time } & Time 1 & $184 \pm 105$ & $210 \pm 144$ & $197 \pm 117$ \\
\hline & Time 2 & $175 \pm 99$ & $222 \pm 142$ & $199 \pm 112$ \\
\hline \multirow[t]{2}{*}{ Sleep } & Time 1 & $584 \pm 71$ & $629 \pm 76$ & $607 \pm 59$ \\
\hline & Time 2 & $585 \pm 70$ & $626 \pm 72$ & $606 \pm 61$ \\
\hline \multicolumn{5}{|c|}{ Accelerometer measured (minutes) } \\
\hline Energetic play & & $31 \pm 15$ & $42 \pm 26$ & $33 \pm 16$ \\
\hline Total movement & & $361 \pm 72$ & $446 \pm 106$ & $377 \pm 80$ \\
\hline Sedentary time & & $437 \pm 89$ & $448 \pm 101$ & $437 \pm 86$ \\
\hline Sleep duration & & $507 \pm 69$ & $509 \pm 93$ & $505 \pm 63$ \\
\hline
\end{tabular}

reinforcement from other adults" scale. This result could be explained, at least in part, by the disparate content of the items. One of the items asked parents to rate their confidence to get their child to be physically active at home and did not refer to other adults in the child's life. Another item asked about other adults in their child's life enforcing rules about screen time - a completely different movement behavior from physical activity. In relation to the poor internal consistency of the "maladaptive activities on sleep" scale, the original validation study reported evidence that the items functioned as a unidimensional scale; nevertheless, it presented lower internal consistency $(\alpha=0.69)$ than the other bedtime routine scales $(\alpha=0.74-0.90)[26]$. In the current study, the low internal consistency was predominantly driven by the responses to the items about 'watching TV' and 'playing video games' in the hour before going to bed, which exhibited negative factor loadings. This suggests that these two items were not assessing the same underlying construct and that, within our sample, the frequency of screen-based activities prior to bedtime was unrelated to the frequency of other activities thought to stimulate children before bed and delay sleep onset and quality (e.g., playing active games and watching television). However,

Table 4 Test-retest intra-class correlation coefficients and 95\% confidence intervals for the parent reported children's movement behaviors

\begin{tabular}{llll}
\hline & $\begin{array}{l}\text { Weekdays } \\
\text { ICC }(\mathbf{9 5 \%} \mathrm{Cl})\end{array}$ & $\begin{array}{l}\text { Weekend days } \\
\text { ICC }(\mathbf{9 5 \%} \mathbf{C l})\end{array}$ & $\begin{array}{l}\text { Average day } \\
\text { ICC }(\mathbf{9 5 \%} \mathrm{CI})\end{array}$ \\
\hline Physical activity & $0.92(0.87,0.94)$ & $0.97(0.95,0.98)$ & $0.96(0.95,0.98)$ \\
Screen time & $0.85(0.77,0.90)$ & $0.93(0.89,0.95)$ & $0.94(0.90,0.96)$ \\
Sleep & $0.94(0.90,0.96)$ & $0.90(0.84,0.93)$ & $0.93(0.90,0.96)$ \\
\hline
\end{tabular}

Legend: CI Confidence intervals, ICC Intraclass correlation coefficient when these two items were deleted, Omega only increased to $0.58-0.59$, which is still below acceptable.

Overall, ICCs for the parenting practices scales and the parent reported child behaviors were high. Only the scale "logistic support for sports" did not demonstrate acceptable test-retest reliability. The low correlation observed between repeat assessments of this scale is likely a function of floor effects and restriction of range. In contrast to many high-income countries, there is no provision of organized sport or physical activity programs for Brazilian children under the age of five [36]; and there are no opportunities for parents to watch their child during training sessions or competitions. Furthermore, families in this study were from low-income communities, thus paying fees for the child to have sports lessons, classes, or play organised sports was not relevant.

Parent reported child physical activity was positively correlated with objectively measured total movement and energetic play, while inversely correlated with screen time. Interestingly, the validity coefficients observed in the present study were considerably larger in magnitude than those reported by Burdette et al. [27] for children in the United States $(r=0.20)$. The discrepancy in findings may be attributable, at least in part, to differences in the accelerometer data processing methods. Burdette et al [27] used the average vector magnitude recorded by the RT3 tri-axial accelerometer as a criterion measure of physical activity which serves as an indicator of the total volume of physical activity and not the type and intensity of physical activity in which children were participating. In the current study, a validated, state-of-the-art machine learning physical activity classification model for free living pre-schoolers was applied to the accelerometer data to derive physical activity metrics that captured both overall movement and time in energetic play 
Table 5 Spearman correlations between parent report measures of child physical activity, screen time and sleep, and accelerometer measured children's movement behaviors

\begin{tabular}{|c|c|c|c|c|c|}
\hline & & \multicolumn{4}{|c|}{ Weekdays (Spearman rho) } \\
\hline & & Sedentary time & Energetic play & Total movement & Sleep \\
\hline \multirow[t]{2}{*}{ Physical activity } & $\mathrm{T} 1$ & -0.37 & 0.39 & 0.46 & 0.14 \\
\hline & $\mathrm{T} 2$ & -0.33 & 0.40 & 0.40 & 0.14 \\
\hline \multirow[t]{2}{*}{ Screen time } & $\mathrm{T} 1$ & 0.21 & -0.27 & -0.32 & -0.12 \\
\hline & $\mathrm{T} 2$ & 0.26 & -0.42 & -0.40 & -0.15 \\
\hline \multirow[t]{3}{*}{ Sleep } & $\mathrm{T} 1$ & -0.30 & 0.19 & 0.19 & 0.29 \\
\hline & $\mathrm{T} 2$ & -0.20 & 0.16 & 0.13 & 0.22 \\
\hline & & \multicolumn{4}{|c|}{ Weekend Days (Spearman rho) } \\
\hline \multirow[t]{2}{*}{ Physical activity } & $\mathrm{T} 1$ & -0.23 & 0.29 & 0.29 & 0.07 \\
\hline & $\mathrm{T} 2$ & -0.23 & 0.30 & 0.33 & 0.07 \\
\hline \multirow[t]{2}{*}{ Screen time } & $\mathrm{T} 1$ & 0.25 & -0.29 & -0.29 & 0.04 \\
\hline & $\mathrm{T} 2$ & 0.20 & -0.26 & -0.25 & -0.01 \\
\hline \multirow[t]{3}{*}{ Sleep } & $\mathrm{T} 1$ & 0.13 & 0.06 & 0.10 & -0.01 \\
\hline & $\mathrm{T} 2$ & 0.12 & 0.02 & 0.14 & -0.05 \\
\hline & & \multicolumn{4}{|c|}{ Average of Weekday and Weekend Day (Spearman rho) } \\
\hline \multirow[t]{2}{*}{ Physical activity } & $\mathrm{T} 1$ & -0.31 & 0.39 & 0.44 & 0.05 \\
\hline & $\mathrm{T} 2$ & -0.30 & 0.39 & 0.41 & 0.07 \\
\hline \multirow[t]{2}{*}{ Screen time } & $\mathrm{T} 1$ & 0.26 & -0.37 & -0.39 & -0.11 \\
\hline & $\mathrm{T} 2$ & 0.24 & -0.41 & -0.41 & -0.14 \\
\hline \multirow[t]{2}{*}{ Sleep } & $\mathrm{T} 1$ & -0.11 & 0.18 & 0.16 & 0.15 \\
\hline & $\mathrm{T} 2$ & -0.03 & 0.11 & 0.12 & 0.07 \\
\hline
\end{tabular}

Legend: In bold type $=p \leq 0.05 ; \mathrm{T} 1=$ Time $1 ; \mathrm{T} 2=$ Time 2

[30]. Therefore, the criterion physical activity measure used in the current study may have had less random measurement error, resulting in stronger associations between self-reported and device-based measures of children's physical activity behaviour.

As evidence of concurrent validity, parent reported child screen time was positively correlated with objectively measured sedentary time, and inversely correlated with total movement and energetic play. However, the amount of child screen time reported by parents warrants discussion. On average, parents reported their child as engaged in screen time for three hours per day (175 - 184 minutes) on weekdays and just over three and a half hours per day ( 210 - 222 minutes) on weekend days. Only $14 \%$ of children in this sample met the WHO sedentary screen time recommendation of less than 1 hour/day [11]. These findings are consistent with other studies conducted in preschool-aged children from South America. In a study of 302 Brazilian children under six, de Carvalho Cremm et al. [37] reported that $61 \%$ of children watched television for more than 2 hours daily. A cross-sectional study investigating 45 preschool- aged children from Chile, indicated that $100 \%$ of children spent more than 2 hours in front of television daily [38]. Finally, an Argentinian study of 183 children aged 5 years and younger reported that $40 \%$ of children spent more than 2 hours on screen time daily [39]. Therefore, our results, supported by other findings from studies conducted in other LMIC, suggests that the majority of young children in South America are not meeting the global recommendation for daily screen time. This finding underscores the urgent need for the development of effective parenting interventions to reduce screen time in preschool-aged children in South American countries, and indeed in similar LMICs.

Parent reported night-time sleep duration was significantly correlated with accelerometer measured sleep duration on weekdays, but not weekends. This finding could be a result of parents being more able to recall sleep duration on weekdays because children follow a routine during the week. This contrasts with weekend nights, when there may be no routine in place and parents have difficulty recalling their child's bedtime and wake up time. In addition, because of the seven-day monitoring protocol, some children (9\%) did not have actigraphy-based estimates of sleep duration on both weekend nights. This may have negatively impacted the reliability of the calculation of weekend sleep duration. 
Although significant positive correlations were observed between the two, there were substantial differences between the parent reported and accelerometer measured children's movement behaviors. However, such differences are expected given that the self-report measures and device-based measures assessed different outcomes. Regarding physical activity behavior, the Burdette recall instrument asked parents to report outdoor playtime [27], while the data obtained from the accelerometer measured movement time regardless of the child's physical location. Reporting time in outdoor play is therefore a slightly different construct to accelerometer measures of total movement and energetic play. When a child is outside it does not necessarily mean that the child is being active as they could be engaged in sedentary behaviors or intermittent light intensity activities requiring little movement. In relation to screen time, parents reported their child's exposure to screenbased devices on weekdays and weekend days. However, the accelerometer measured total sedentary time across the day and did not consider exposure to screens. Screen time may not be entirely sedentary time, and not all sedentary time involves screens.

This study had several strengths. To our knowledge, this is the first study to evaluate the concurrent validity, internal consistency reliability, and test-retest reliability of measurement tools to assess parenting practices and children's movement behaviors in a LMIC country, using measurement tools that have gone through a rigorous process of translation and cognitive testing prior to validation [24]. Second, this study recruited a diverse sample from urban and rural disadvantaged Brazilian families with low literacy levels. Lastly, concurrent validity was assessed using advanced machine learning accelerometer data processing methods, allowing for a detailed examination of children's physical activity, sedentary behavior, and sleep duration. There were however several limitations. The results were obtained on a relatively small sample from only two communities of Brazil. Therefore, the results may not be generalizable to all communities in Brazil and other LMIC. Further studies are needed to evaluate the psychometric properties of these measurement tools in larger more diverse samples, and in other LMIC communities. Additionally, 91\% of the participants completed the survey as an interview and the results may not be fully generalizable to situations where the instrument is completed as a selfadministered questionnaire. However, the participants had low levels of formal education and lacked the literacy skills required to read and complete the measures on their own. It is very likely that future studies may have to use the same mode of administration if they wish to complete studies in families from rural areas in LMIC.

\section{Conclusions}

In conclusion, previously validated measures of children's movement behaviors and parenting practices, translated and culturally adapted for use in Brazilian families, exhibited strong evidence of concurrent validity, internal consistency reliability, and test-retest reliability. Considering these findings, the measures could be used in studies to examine the children's compliance with 24hour movement guidelines, and the relationships between parenting practices and children's obesity-related behaviors in disadvantaged families from Brazil. Future studies should evaluate the psychometrics properties of these scales in families living in other LMIC's who are also facing childhood obesity challenges.

\section{Abbreviations}

BRQ: Bedtime routine questionnaire; ECEC: Early Childhood Education and Care; LMIC: Low-middle income countries; WHO: World Health Organization

\section{Supplementary Information}

The online version contains supplementary material available at https://doi. org/10.1186/s12874-021-01320-y.

\section{Additional file 1.}

Acknowledgements

The authors are grateful to all the parents and preschool children who participated in the study; the Department of Education and Health of the municipality of Caruaru, and the Child Care Directors for supporting the study; and the staff for data collection.

\section{Authors' contributions}

WSFG, ST and RB designed the study; WSFG, PICL, MTV recruited the participants and contributed to data collection; WFG, RB and ST analyzed and interpreted the data; WFG drafted the manuscript; WFG, RB and ST critically reviewed and edited the manuscript; all authors read and approved the final manuscript.

\section{Funding}

WFG is supported by a National Health and Medical Research Council Centre of Research Excellence in the Early Prevention of Obesity in Childhood, Grant/Award Number: APP1101675.

\section{Availability of data and materials}

The dataset supporting the conclusions of this article can be made available upon request after approval by the authors. Please direct inquiries to widjane.ferreiragoncalves@hdr.qut.edu.au.

\section{Declarations}

Ethics approval and consent to participate

Parents who agreed to participate returned a signed informed consent form to the principal investigator. For parents with low literacy level and their children informed consent was obtained from a legally authorized representative. The study received ethical approval from the Human Research Ethics at Queensland University of Technology, Brisbane - Australia (Approval No. 1800001141). We confirm that all methods were carried out in accordance with relevant guidelines and regulations of the Human Research Ethics Committee at Queensland University of Technology.

Consent for publication

Not applicable.

Competing interests

The authors declare that they have no competing interests. 


\section{Author details}

${ }^{1}$ Centre for Children's Health Research, School of Exercise and Nutrition Sciences, Queensland University of Technology, Brisbane, Australia. ${ }^{2}$ Federal University of Pernambuco, Recife, PE, Brazil. ${ }^{3}$ Centre for Children's Health Research (CCHR), Level 6, 62 Graham St, South Brisbane, QLD 4101, Australia.

Received: 2 February 2021 Accepted: 18 May 2021

Published online: 24 June 2021

\section{References}

1. World Health Organisation. Global strategy on diet, physical activity and health. Childhood overweight and obesity. Geneva: WHO; 2020.

2. United Nations Children's Emergency Fund. WHO, World Bank. Levels and trends in child malnutrition: UNICEF-WHO-World Bank joint child malnutrition estimates. New York: UNICEF; 2017.

3. Ministério da Saúde. Sistema de vigilância alimentar e nutricional (SISVAN) Módulo gerador de relatórios públicos: estado nutricional dos indivíduos acompanhados por período, fase do ciclo da vida e índice. Brasília: Ministério da Saúde; 2014. p. 38.

4. Magnussen CG, Smith KJ, Juonala M. When to prevent cardiovascular disease? As early as possible: lessons from prospective cohorts beginning in childhood. Curr Opin Cardiol. 2013:28:561-8.

5. Pulgaron ER. Childhood obesity: a review of increased risk for physical and psychological comorbidities. Clin Ther. 2013;35:A18-32.

6. Reilly JJ, Kelly J. Long-term impact of overweight and obesity in childhood and adolescence on morbidity and premature mortality in adulthood: systematic review. Int J Obes. 2011;35:891-8.

7. World Health Organization. What are the health consequences of being overweight? Geneva: WHO; 2013

8. World Health Organization. Why does childhood overweight and obesity matter? Geneva: WHO; 2018

9. Nader PR, O'Brien M, Houts R, Bradley R, Belsky J, Crosnoe R, et al. Identifying risk for obesity in early childhood. Pediatrics. 2006;118:e594-601.

10. Chaput J-P, Carson V, Gray CE, Tremblay MS. Importance of all movement behaviors in a 24 hour period for overall health. Int J Environ Res Public Health. 2014;11:12575-81.

11. Kuzik N, Poitras VJ, Tremblay MS, Lee E-Y, Hunter S, Carson V. Systematic review of the relationships between combinations of movement behaviours and health indicators in the early years (0-4 years). BMC Public Health. 2017; 17:849.

12. World Health Organization. Guidelines on physical activity, sedentary behaviour and sleep for children under 5 years of age. Geneva: WHO; 2019.

13. Guerra PH, Barbosa Filho VC, Almeida A, Silva LS, Pinto MTV, Leonel RM, Ribeiro EHC, Florindo AA. Systematic review of physical activity and sedentary behavior indicators in south-american preschool children. Rev Paul Pediatr. 2019;38:e2018112.

14. Lu L, Xun P, Wan Y, He K, Cai W. Long-term association between dain consumption and risk of childhood obesity: a systematic review and metaanalysis of prospective cohort studies. Eur J Clin Nutr. 2016;70:414-23.

15. Roman-Vinas B, Chaput JP, Katzmarzyk PT, Fogelholm M, Lambert EV, Maher C, et al. Proportion of children meeting recommendations for 24-hour movement guidelines and associations with adiposity in a 12-country study. Int J Behav Nutr Phys Act. 2016;13:123.

16. Felso R, Lohner S, Hollody K, Erhardt E, Molnar D. Relationship between sleep duration and childhood obesity: Systematic review including the potential underlying mechanisms. Nutr Metab Cardiovasc Dis. 2017;27:75161.

17. de Jong E, Visscher TL, HiraSing RA, Heymans MW, Seidell JC, Renders CM. Association between TV viewing, computer use and overweight, determinants and competing activities of screen time in 4- to 13-year-old children. Int J Obes. 2013;37:47-53.

18. Patrick $\mathrm{H}$, Hennessy $\mathrm{E}$, McSpadden $\mathrm{K}, \mathrm{Oh}$ A. Parenting styles and practices in children's obesogenic behaviors: scientific gaps and future research directions. Child Obes. 2013:9(Suppl):S73-86.

19. El-Sheikh M. Sleep and development: Familial and socio-cultural considerations. Oxford Scholarship Online, 2011.

20. Masse LC, O'Connor TM, Tu AW, Hughes SO, Beauchamp MR, Baranowski T. Conceptualizing physical activity parenting practices using expert informed concept mapping analysis. BMC Public Health. 2017;17:574
21. O'Connor TM, Cerin E, Hughes SO, Robles J, Thompson DI, Mendoza JA, et al. Psychometrics of the preschooler physical activity parenting practices instrument among a Latino sample. Int J Behav Nutr Phys Act. 2014;11:3.

22. Trost SG, Loprinzi PD. Parental influences on physical activity behavior in children and adolescents: a brief review. Am J Lifestyle Med. 2011;5(2):17181.

23. Rhodes RE, Guerrero MD, Vanderloo LM, et al. Development of a consensus statement on the role of the family in the physical activity, sedentary, and sleep behaviours of children and youth. Int J Behav Nutr Phys Act. 2020;17: 74

24. Goncalves W, Byrne R, Lira P, Viana M, Trost SG. Cross-cultural adaptation of instruments measuring children's movement behaviors and parenting practices in Brazilian families. Int J Environ Res Public Health. 2021;18:239.

25. Vaughn AE, Hales D, Ward DS. Measuring the physical activity practices used by parents of preschool Children. Med Sci Sports Exerc. 2013;45:236977.

26. Henderson JA, Jordan SS. Development and preliminary evaluation of the bedtime routines questionnaire. J Psychopathol Behav Assess. 2010;32:27180.

27. Burdette HL, Whitaker RC, Daniels SR. Parental report of outdoor playtime as a measure of physical activity in preschool-aged children. Arch Pediatr Adolesc Med. 2004:158:353-7.

28. Hesketh KD, Campbell K, Salmon J, McNaughton SA, McCallum Z, Cameron A, et al. The Melbourne infant feeding, activity and nutrition trial (InFANT) program follow-up. Contemp Clin Trials. 2013;34:145-51.

29. Taylor RW, Gray AR, Heath A-LM, Galland BC, Lawrence J, Sayers R, et al. Sleep, nutrition, and physical activity interventions to prevent obesity in infancy: follow-up of the Prevention of Overweight in Infancy (POI) randomized controlled trial at ages 3.5 and 5 y. Am J Clin Nutr. 2018;108: 228-36.

30. Ahmadi MN, Pavey TG, Trost SG. Machine learning models for classifying physical activity in free-living preschool children. Sensors. 2020;20:4364.

31. Van Hees VT, Sabia S, Jones SE, Wood AR, Anderson KN, Kivimäki M, et al. Estimating sleep parameters using an accelerometer without sleep diary. Sci Rep. 2018:8:12975.

32. Ahmadi MN, Nathan N, Sutherland R, Wolfenden L, Trost SG. Non-wear or sleep? Evaluation of five non-wear detection algorithms for raw accelerometer data. J Sports Sci. 2019;38:399-404.

33. Hayes AF, Coutts JJ. Use omega rather than Cronbach's alpha estimating reliability. But.... Commun Methods Meas. 2020;14:1.

34. Koo TK, Li MY. A guideline of selecting and reporting intraclass correlation coefficients for reliability research. J Chiropr Med. 2016;15:155-63.

35. Kelly K. Methods for the behavioral, educational, and social sciences: an R package. Behav Res Methods. 2007:39:979-84.

36. Ministério da Educação. Parâmetros nacionais de qualidaed da educação infantil. Ministério da Educação. Secretaria de Educação Básica - Brasília. Brasil.

37. de Carvalho CE, Leite FHM, de Abreu DSC, de Oliveira MA, Scagliusi FB, Martins PA. Factors associated with overweight in children living in the neighbourhoods of an urban area of Brazil. Public Health Nutr. 2012;15: 1056-64.

38. López MÁ, Llanos IP, Díaz JM. La televisión y su relación con el estado nutricional y frecuencia de consumo en niños de un conjunto habitacional de Talca, Chile. Rev Chil Nutr. 2012;39:129-34.

39. Roda G, Silvina SC, Mariana C, Daiana A, Salvador Cabrera S, Campisi M, et al. Resultados de la encuesta de hábitos alimentarios y antecedentes familiares en Centros de Desarrollo Infantil del Municipio de Merlo. Diaeta (B Aires). 2016;34:41-7

\section{Publisher's Note}

Springer Nature remains neutral with regard to jurisdictional claims in published maps and institutional affiliations. 